yet their strained relation becomes at once evident when their energy is taxed in the struggle with an irritant.

It follows, then, from the foregoing considerations that what is commonly called "hay-fever" is not, as alleged, the result of pollen pure and simple, or a special form of disease. Two distinct varieties must be distinguished-the one merely a catarrhal affection, due to pollen plus the other solid constituents of the air ; the other, an erysipelatous inflammation of the upper parts of the respiratory tract, considerably aggravated by mechanical irritants, which at no other time exist in the air in such abundance as in spring and summer.

Too much importance cannot be attached to a just understanding of the nature of the disease; for undoubtedly the so-called hay fever is the most common forerunner of typical bronchial asthma. All asthmatics declare that before their present disease has assumed its striking characteristics, they had either been for years subject to "hay fever"; or if they trace their troubles to what is loosely called "colds" and "bronchitis," they invariably maintain that they had been worse in the summer than in the winter. It has been songht to establish a diagnosis between hay asthma and bronchial asthma upon the ground that the dyspnueal paroxysms of the former occur only during the day, while those of the latter occur at night. But by Blackley's own slowing such is not in variably the case. He himself reports that a lady whom he observed had to sit up for twelve or fourteen consecutive nights. Il On the other hand, Phoobus, from an analysis of his cases, comes to the opposite conclusion-that in hay fever the dyspncea increases as the day wears on, and assumes its greatest intensity at night. ${ }^{12}$ But in the ordinary form of asthma the attacks arise at all times, by no means of tener in the night than in the day; nor is there between the asthma in summer and that in winter the least difference either in its symptorns or in its cliaracteristic pathological products. Only it has not been sufficiently insisted upon that asthma is, on the whole, by far more prevalent in the summer than in the winter-a fact which has been remarked also by Trousseau, who has consequently called it "uno maladie d'été." 13

If forewarned is to be forearmed, it is first of all renuisite to distinguish well between the various forms of the disease. It is obviously easier to cope with a pathological process so long as it is limited to an accessible mucous membrane than to attempt its removal after its invasion of the deeper part of the air passages, and the infliction of irreparable mischief. But in order to obtain that object in view, the diagnosis of the disease must not be entirely based on the state of the weather. The inflammatory processes of the upper part of the air passages are not necessarily a "cold" because they occur in the winter, or "hay fever" because they are seen during the hay season. Each case must be judged according to its inerits. The affection, which is entirely localised to the nose and eyes, may be probably due to a thermal or mechanical irritant ; the one that simultaneously or rapidly invades the entire upper part of the respiratory tract is an erysipelatous affection which demands all care and attention, especially in chillren with signs of previous rickets.

It is foreign to the present purpose to enter into the subject of treatment; but considering the gravity of the issue, it is difficult to forbear one word of warning on the methods now in vogue. There is no good rround for hailing with unbounded delight, as a specific for the paroxysms of hay fever, cocaine or similar remedies, which indeed suppress the manifestation of the disease, but leave its cause in undisturbed activity. Let there be no misunderstanding. No one engaged in practice could for a moment dispense with a purely symptomatic treatment. Unfortunately it happens but too often that, when we are best acquainted with the pathology of any form of disease, the nuost we can do is to alleviate the symptoms. It is a cruel mockery, however, to dally with insufficient measures when otherwise some permanent benefit may be obtainable. Nor is any useful end served by galvanic cauterisation of the mucous membrane of the nose and pharynx or by the destruction of the varicose veins, which, indeed, may be seen on the bacli of the throat. Such proceeding is just as rational and just as indicated as to destroy the dilated veins in the legs, when the circulation of its deeper parts is temporarily interfered with.

Wimpole-street, W.

11 Op. cit., p. 184.12 Op. cit.

13 Clinique Nedicale, 1868, tome ii., 1. 452.

\section{AN ANOMALOUS CASE OF SAIIVARY CALCULUS.}

BY EDMUND OWEN, F.R.C.S.

A LADY recently came under my care for a troublesome but painless swelling of the left theek. The medical man who sent her to me suggested that it was a case of distension of a greatly dilated parotid duct, possibly caused by a salivary calculus. Unfortunately this gentleman did not accompany her on her visit to me, and on the most careful examination I could detect no calculus, but found the cheek of that side somewhat prominent and unsightly. The lady said that she had been bothered by a swelling in that cheek ever since she was four years old, and that sometimes after a meal it was much more conspicuous than it was at that time. She was determined to have something done for the swelling, and I was content to hold my diagnosis as to the exact nature of the soft tumour in suspense until I could make a thorough exploration, which I did a few days later, Dr. Prickett kindly helping. There was then a rounded, doughy swelling of the one cheek, but no calculus was discoverable. Ansesthesia having been produced, and the jaws being separated by Mason's gag, an incision was made throngh the mucous lining of the mouth and the luccinator, a lobulated piece of yellow fat at once protruding. Gentle traction being made on this, a lipoma of considerable size readily left its bed between the buccinator and masseter muscles. The cheek was then flat like the other. It seemed as if no further treatment would be required, and nothing more was attempted. Within a few days, however, it became evident that the patient did not share our favourable view of the case. She said that on several occasions the cheek had swollen as badly as ever. Never happening to see the cheek, however, when swollen as she described, I thought it not improbable that her imagination supplied her with such evidence as I failed to discover. She was therefore advised to return home and to apply again should she meet with further inconvenience. In a short while she duly presented herself, and directed attention to a small, hard substance, which shifted its position over the masseter; it was evidently the salivary calculus of which her medical attendant had spoken. An attempt was promptly made to extract it through the mouth by reopening the old wound, but on introducing a pair of forceps the concretion slipped away and so effectually concealed itself that further search for it on that occasion had reluctantly to be abandoned. On a subsequent occasion on which the calculus was discovered I leisurely examined it from the outside of the cheek, and found that the limit of its journey forwards was just beyond the hinder border of the masseter, and that with the slightest touch it slipped back in to a dilatation of Stenson's duct, which formed a wide chamber behind the angle and ramus of the jaw. From this pouch the calculus could be swept out by firm pressure. Sometimes it was no easy matter to bring it out again, as it hid itself on the inner aspect of the mandibular angle in the capacious chamber. Having been twice disappointed in the treatment of the case when operating through the buccinator, I determined to cut straight down on to the calculus through the cheek, having chased it forwards and secured it by the finger pressed over the hinder part of the masseter. In this way its extraction proved a simple matter. The skin wound, which was closed with horsehair sutures, healed by first intention, giving no trouble whatever as regards leakage of saliva, and leaving a scar which, from the patient's point of view as well as the surgeon's, is now hardly noticeable. The calculus was a phosphatic concretion of the size and shape of a small date stone.

Remarts. - No one who has carefully dissected the face can fail to have noticed the pad of yellow fat which is lodged between the masseter and buccinator, the little pellets of which obeyed the slightest touch of his forceps. But in the case under consideration the mass of fat far exceeded the normal aniount, and when drawn out through the mouth constituted a lipoma of a very respectable size. Moreover, the swelling which had previously disfigured that cheek had so entirely disappeared that I felt justified in saying that the operation would prove entirely successful. Probably the irritation caused by the salivary calculus had 
brought about an over-nutrition of the fatty pad and so determined its hypertrophy, the other cheek remaining of normal size and appearance. Certainly the removal of the calculus alone would not have restored the symmetry, and had I extracted the concretion on the first occasion I might have hesitated to proceed to the ablation of the buccal lipoma, even if I had made a correct diagnosis of the nature of that swelling. Thus, as possibly not infrequently happens, failure on the part of the surgeon either in the way of diagnosis or treatment, worked for the good of the patient. As regards the removal of the calculus from the outside of the cheek, it is not an operation which one would generally recommend lest a troublesome salivary fistula should result, but, seeing the perfect way in which the wound healed the danger of such a contingency is probably over-rated.

Great Cumberland-place, $w$.

\section{Clinital atotes:}

\section{MEDICAL，SURGICAL，OBSTETRICAL，AND THERAPEUTICAL.}

\author{
SIMULTANEOUS FRACTURE OF BOTH \\ CLAVICLES. \\ By Herrert W. Page, \\ SCRGEON TO ST. MARY'S HOSPITAL.
}

THE interesting case recorded last week by my colleague Mr. Owen reminds me of one which was under my care in the Cumberland Infirmary in 1873 , and which may be added to the list. A railway porter was brought one night some fifty miles to the hospital under the supposition that he had received severe internal injuries, for his shoulders had been caught sideways between the buffers of two waggons, he was much collapsed, and had great pain at the upper part of the chest. No examination had been made. On admission it was found that the only injury was oblique fracture of both clavicles at corresponding points-the middle of each bone. There was the usual displacement, and as this was most easily and perfectly rectified by lying flat on the back without a pillow for the head, so was he treated, and he presently left with both bones firmly united.

While recording this example of a very rare form of injury I may refer to another which is equally, if indeed it be not more uncommon, and which $I$ had the opportunity of seeing when dresser at the London Hospital in 1869 . A woman was admitted with dislocation of her right clavicle at both ends. I forget the precise mode in which the accident had happened, but it had been very severe, and the clavicle was separated from its attachments at both ends, and came to lie almost at right angles to its natural position-the acromial end backwards, the sternal end forwards. The reduction of this dislocation was extremely difficult, and was not entirely successful.

\section{NOTE ON PERCHLORIDE OF MERCURY PELLETS.}

By C. J. Bond, F.R.C.S.

ETRGON TO THE MEICESTER INIIRMARX.

Althotgh not perhaps as fully appreciated as they deserve, the convenience and value of perchloride of mercury in the form of pellets for making antiseptic solutions of different strength are so great that I wish to bring to notice a preparation in which equal parts of perchloride of mercury and chloride of sodium form one pellet, each containing about four grains and a half of the perchloride; these dissolve in a pint of warm water in about three minutes, thus forming a solution of 1 in 2000 . The advantages that $I$ claim for this form of pellet-namely, the combination with chloride of sodium instead of the usual chloride of ammonium-are: (1) That solutions of perchloride and chloride of sodium with hard water containing lime do not turn milky, or throw down a precipitate of probably oxychloride of mercury, as is often the case with Eolutions made with the double salt of ammonium chloride and mercury after stand ing a short time. This is important, as it is often impos sible in private practice to obtain distilled water, and a solution so precipitated loses much of its antiseptic value. (2) The solution is neutral and not acid, as in the case of the ammonium salt ; moreover, chloride of sodium is a natural constituent of the blood serum and other fluids of the body. The perchloride of mercury alone, and the ammonio-chloride and the sodium salt, all precipitate albumen, and conse quently throw down a milky precipitate when in contact with serum in wounds; the addition of a little free acid will redissolve this, and it would thus appear at first as if the acidity of the ammonium salt would be here of value, but it is not so, the ammonium salt precipitating equally with the others. Moreover, the above advantages apply also in the case of strong standard solutions of perchloride and of the liq. hyd. perchloridi of the Pharmacopoia, which is practically a solution of a double salt of ammonium chloride and perchloride of mercury of the strength of 1 in 1000 . Although it is no doubt necessary to use some salt, such as the ammonium chloride, to prevent the perchloride of mercury from decomposing into calomel and free $\mathrm{HCl}_{2}$ which it would do if used alone in solution, and also for the purpose of increasing the solubility of the perchloride in strong solutions, yet it seems to me that both these objects are equally obtained by using the sodium chloride salt, and, moreover, without the disadvantages of the milky precipitate when dispensing with ordinary non-distilled water, or the crystallisation and deposit round the stopper of the bottle, which occur with strong solutions of the ammonium salt. In fact, it would seem desirable that the Pharmacopœial preparations should be made with chloride of sodium and not of ammonium.

Leicester.

URETHRAL CALCULUS OF LARGE SIZE IN A BOY TWO YEARS AND A HALF OLD; OPERATION ; CURE.

By A. IRWin Bolton, M.B., A.B.

S. F_- a fine healthy Bulgar boy aged two years and a half came under my care on June 1st, 1890, suffering from anuresis and frequent painful spasm in the region of the bladder. There was also continuous priapism, great tenesmus at the enus, and consequent difficulty of defecation. Suspecting stone 1 passed a small sound, and found a calculus lodged in the urethra close to the bladder. The stone was felt to be firmly impacted in the canal, but still there was constant stillicidium urinæ. I advised immediate operation, but this would not be heard of by the parents. As an alternative I prescribed frequent hot camomile baths, and bromine with sedatives and soda internally. The case went on so from day to day, spasms of the urethra being frequent and violent. The child, during these spasms, resembling, as the mother remarked, a woman in the pains of labour. Sleep was seldom obtained, and then only for a minute or so at a time. I was frequently called to visit and preseribe until June 20th, when I refused to attend further unless allowed to operate. The assent was given. At this time the stone had advanced into the scrotal portion of the urethra, and had become securely fixed. The anuresis also now became complete and the bladder distended. The child having been anrsthetised (equal parts of ether and chloroform), I cut direct on to the stone through the raphe of the scrotum, using a squeezing pressure forwards, and with the aid of a probe the stone came away. A No. 4 olivary elastic catheter was at once passed into the bladder, and the incision closed with carbolised catgut sutures. Strict antisepsis was aimed at. The child was securely bandaged and bound to its cot, and I gave orders that it should so be retained until I came the next morning. On my visit the following morning I found the patient had been unfastened and the catheter withdrawn because he cried so much. The mother said it did not matter, as the child could urinate freely. I found this statement only too true, for he urinated more through the wound than the urethral orifice. I now passed again the eatheter, and fortunately without difficulty. The wound was well cleaned with corrosive sublimate solution, and the child securely bound in its cot. On June 25 th the wound had healed and the child was well. 